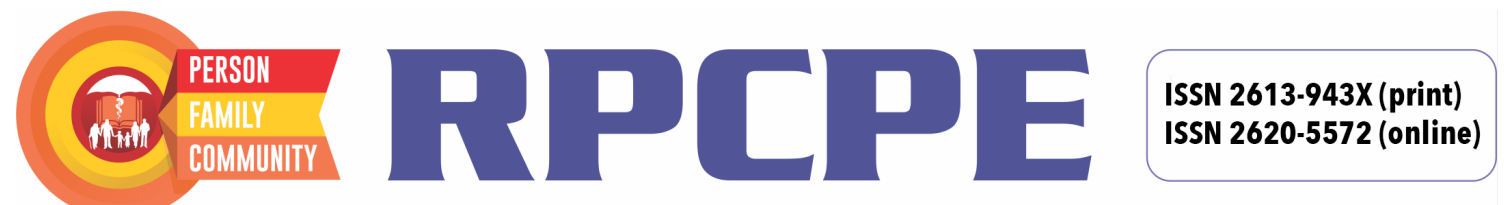

Review of Primary Care Practice and Education

Journal Homepage:

https://jurnal.ugm.ac.id/rpcpe

(Kajian Praktik dan Pendidikan Layanan Primer)

\title{
New Civilization in the Post-Covid-19 Health World \& Lesson Learned from the Netherlands
}

\author{
Armyn Nurdin ${ }^{1}$, Tjay $\operatorname{Tan}^{2}$, Isti Ilmiati Fujiati ${ }^{3}$
}

${ }^{1}$ Department of Community Medicine; Medical School; Hasanuddin University; Indonesia
${ }^{2}$ Huis Art - Diaspora; Maastricht University; The Netherlands
${ }^{3}$ Department of Community Medicine; Medical School; University of Northern Sumatra; Indonesia

Presented at the webinar organized by the collaboration between the Indonesian Family Medicine College, the Indonesian Family Doctors Association, the Indonesian Society of Teachers in Family Medicine, the Review-Journal on Primary Care Practice and Education, and the Center for Policy Management, the Faculty of Medicine, Gadjah Mada University on April 15, 2020.

Corresponding Author:

Armyn Nurdin: Department of Community Medicine; Medical School; Hasanuddin University, Jl. Perintis Kemerdekaan KM. 10

Makassar - 90245

E-mail:armyn_nurdin@yahoo.com

To cite this article:

Nurdin A, Tan T, Fujiati II. New Civilization in the Post-Covid-19 Health World \& Lesson Learned from the Netherlands. Rev Prim Care Prac and Educ. 2020; 3(3): 14-21.

\section{INTRODUCTION}

\section{New Civilizations in the Post-Covid-19 World Health}

There are several possibilities that will happen after the Covid-19 outbreak ends. This is the other side of the Covid-19 pandemic. There is a term called see the unseen, or seeing something before it happens. An illustrative example is that everyone sees the apple falling down, but only one person sees why or what causes the apple to fall down. This is Isaac Newton. Based on this phenomenon, the formula for the gravitational force or the gravitational force of the earth is triggered. This paper focuses on what might happen in the future.

Indeed, the earth repairs itself in its own way, and that is for the benefit of mankind. The Covid-19 outbreak that is currently happening is a very positive thing for human life. Under the earth there are shifts in the earth's plates which cause tectonic earthquakes. What is the goal? The aim is to stabilize the earth so that an asteroid collision does not occur. There is a plague on earth, what does it mean? Its meaning is to improve human life. So, let's interpret the current outbreak as something positive. Previously in Europe, there were millions of deaths due to PES disease. At that time, most farmers died, so the land owners were short of labor. What is the meaning? First, farmers have a high bargaining position. Second, after the plague occurred, then there was the collapse of feudalism. In the past, peasants worked in a kind of forced labor. Then the modern economic system was born. It was started at that time when farmers were paid in cash which had never happened before. This was the beginning of the growth of the modern economic system².
Furthermore, due to European difficulties for farmers, they developed agricultural technology to replace farmers. This is the beginning of the growth of the industrial revolution ${ }^{3}$. Then, the Europeans left Europe to other continents because Europe was uncomfortable at that time. Then, colonization began. These points have led to the rise of Europe until recently as a developed country. It started at that time when farmers were paid in cash which had never happened before. This was the beginning of the growth of the modern economic system ${ }^{2}$. Furthermore, due to European difficulties for farmers, they developed agricultural technology to replace farmers. This is the beginning of the growth of the industrial revolution3. Then, the Europeans left Europe to other continents because Europe was uncomfortable at that time. Then, colonization began. These points have led to the rise of Europe until recently as a developed country. It started at that time when farmers were paid in cash which had never happened before. This was the beginning of the growth of the modern economic system ${ }^{2}$. Furthermore, due to European difficulties for farmers, they developed agricultural technology to replace farmers. This is the beginning of the growth of the industrial revolution3. Then, the Europeans left Europe to other continents because Europe was uncomfortable at that time. Then, colonization began. These points have led to the rise of Europe until recently as a developed country. Europeans left Europe for another continent because Europe was uncomfortable at that time. Then, colonization began. These points have led to the rise of Europe until recently as a developed country. Europeans left Europe for another continent because Europe was uncomfortable at that time. Then, colonization began. These points have led to the rise of Europe until 
recently as a developed country.

Another example of an epidemic is the former European people after leaving Europe, they colonized. One of them is in the Americas. On the American continent, they carry various diseases that cause the death of people in America, so the population has decreased from 60 million to 6 million. What is the meaning? The meaning is that the forest becomes wider and there is a decrease in $\mathrm{CO} 2$, so that there is a decrease in temperature which causes life to get better.

Actually viruses teach humans many things, but humans don't learn from viruses. In 2002, SARS, there was transmission from mongoose to humans and infected 26 countries. In 2005 there was bird flu, transmission from birds to humans. In 2012, MERS, transmission occurred from camels to humans. In fact, viruses teach humans to be prepared. Prepare for human-to-human transmission, to build better response systems, but humans don't. Then Covid-19 emerged in 2019 and humans failed to handle it properly. This is still droplet contact, not airborne. The future epidemic that will occur is airborne transmission or transmission, this is terrible. Moreover, if there is direct contact, it occurs fecal-oral, and future vector transmission. It will cause a tremendous outbreak, and humans should build response systems from now on. WHO currently does not have a response system to deal with that. Humans don't learn from previous viruses. In the future, this response system must be built.

\section{The Impact of Covid-19 on Various Aspects}

This epidemic had an impact on ideological, political, economic, social and cultural aspects. In terms of ideology, for example, there is a ban on Friday prayers, a ban on worshiping at mosques, and a ban on Umrah. This has confused scholars and threw arguments to one another. Likewise with other religions. What does it mean? Whereas in the future, the integration of science and religion is absolutely necessary to prevent future confusion ${ }^{4}$.

Communication bias. Doctors are taught doctorpatient communication well, but for doctor-community communication, doctors are not adept at it. The proof, physical distancing has actually turned into a stigma or a bad stamp against Covid-19 sufferers. Many residents refused Covid-19 patients who died to be buried near their area, the boarding school children were evicted, layoffs occurred even though they were not suffering from Covid, but their nearby families suffered from Covid-19, so they were laid off.

From an economic perspective, the benchmark interest rate is currently high. Bank Indonesia 7-Day Repo Rate is 5\%, and this makes investment difficult. What is the impact of high benchmark interest rates? The impact is that no one wants to borrow money from the bank because of the high interest rate. The installment interest also increases. Reduced investment $^{5}$, what are the consequences if investment is reduced? Thus, products from industries and products from society will decrease, resulting in a recession in economic growth. The rupiah exchange rate has become weak and there is inflation5. GDP (Gross Domestic Product) is the value of products produced by industry, and GNP (Gross National Product) is the value of products produced by society, this will experience a sluggishness or recession and disrupt social welfare. There will be a significant change to give birth to a new civilization with events like this. Based on this, several scenarios can be seen.

\section{New World Health Civilizations Scenario Post-Covid-19}

The first scenario is decoupling, meaning that there is a break / release. What's off? For example, in the field of Medical Education or Health Education before Covid-19, there were face-to-face lecturers and students in every lesson. Sometimes it is difficult to get lecturers to do e-learning. Lecturers are not satisfied if they are not face to face. Likewise with CSL, still face to face. What are the consequences? It takes a large campus for this. After Covid-19, everyone felt comfortable without being face to face. So, there is an acceleration from the 4.0 industrial revolution. All are comfortable. In some countries, CSL exams have been conducted through games. For example regarding the case of cardiac pulmonary resuscitation. Then students will perform cardiopulmonary resuscitation through games and from there they will get a score. The size of the score depends on their skills in performing cardiopulmonary resuscitation. What does it mean? That the campus, the school, are no longer limited by walls, that the campus is worldwide. Wherever someone is, it is their campus. This means that in the future, tall buildings are no longer needed. Likewise, apart from the health sector, there is no need for multi-tiered offices because that is precisely what ruins the earth. Then, what about health services? Currently face to face between doctors and patients is still ongoing, still close contact. The doctor examines the patient's body, performs a physical examination, and so on. In the future, everything will be entered into the internet or known as IOT, the internet of things ${ }^{6}$. All complete data from patients will be entered into big data. The result is that the algorithm can produce artificial intelligence. Currently, several scientists are developing a barcode on Android-based smartphones. So, if the blood is dripping on the barcode, the complete laboratory results will be presented. Thus, when the barcode is placed on the chest, it can diagnose several diseases without having to perform radiological examinations, pneumonia, and so on. That was the birth of artificial intelligence ${ }^{7}$. If the way to educate lecturers is still like now, then in 10 years students will be confused about this, because what they will face in the next 10 years, 15 years, 20 years is not in accordance with what the lecturer gave in the class. If the blood is dripping on the barcode, the complete laboratory results will be presented. Thus, when the barcode is placed on the chest, it can diagnose several diseases without having to perform radiological examinations, pneumonia, and so on. That was the birth of artificial intelligence ${ }^{7}$. If the way to educate lecturers is still like now, then in 10 years students will be confused about this, because what they will face in the next 10 years, 15 years, 20 years is not in accordance with what the lecturer gave in the class. If the blood is dripping on the barcode, the complete laboratory results will be presented. Thus, when the barcode is placed on the 
chest, it can diagnose several diseases without having to do radiological examinations, pneumonia, and so on. That was the birth of artificial intelligence 7 . If the way to educate lecturers is still like now, then in 10 years students will be confused about this, because what they will face in the next 10 years, 15 years, 20 years is not in accordance with what the lecturer gave in the class.

The second scenario is disruption. Currently, there are so many victims from fellow doctors and other health workers due to Covid-19, so in the future after Covid-19, so that the risk of medical personnel is reduced, it can be replaced by mechanical power. So that doctors and other medical personnel do not make direct contact anymore in some cases, except for certain cases. Medical education must lead there. When doing an injection, for example, at the tip of the needle there is a sensor which, if the patient is nervous, the needle will not enter the body. So, this is to avoid nervousness. Hopefully the patient will be injected, but without feeling the slightest pain. Likewise in making a diagnosis, directly looking at how changes occur in a patient's DNA and all of that is in the big data of medicine.

The third scenario is new science. As a result of this, new sciences or study programs that are needed in the future will emerge. One of the study programs needed in the future is vaccine development. In Indonesia it is still weak, still very weak and we still expect other countries to produce this This must be made by Indonesia itself, making its education. Then medical engineering, this is very salable in the future because this is the future of Medicine. Other sciences are Life Sciences, Immunoinformatics. Life Sciences already exists in several countries including Indonesia. Then also the most important thing going forward in dealing with this outbreak is the thousands of field epidemiologists. Doctors must be educated and trained through simulations of the outbreak. They were sent to the field. Epidemiologyst field,

The fourth scenario is humanity's new agenda. Now the transmission is still droplet, not through the air. What if the transmission is over the air? So the virus will fly everywhere. Then there is another plague that affects the whole world and again humans fail to deal with it if not properly prepared. This is what causes humans to leave the world to look for other planets for their lives that are safer and better. Indonesia will look for islands, countries in the Arctic where viruses or germs cannot thrive, or humans will create a separate, sterile world where germs cannot live there. It is a new human agenda going forward.

The fifth scenario is actually entering what is called the world average ${ }^{8}$. In the future, there is no need for many universities on this earth. For example, when a lecturer teaches, only one campus is enough, and it is followed by students around the world with the existing IT sophistication. It will happen someday. You don't need thousands of universities, just one. Those are some of the foresight. Let's face Covid-19 with pleasure. How happy? That with this epidemic, the world will get better.

Lesson Learned Lesson Learned from the Netherlands of the Netherlands
The first fact is a fact from WHO. Since the beginning of 2020, Covid-19 has been a problem in the world9, and on 27 February 2020 it became the first problem in the Netherlands. Initially, people thought that Covid-19 would still be in the Netherlands for a long time. So that people are not so alert. On February 27, a positive case of Covid-19 was found for the first time. Until now (data as of April 14, 2020 ), nearly 3,000 people died out of the 28,000 people who were diagnosed with Covid-19. The suspect with Covid-19 symptoms is 15000 .So, nearly 45,000 people have Covid-19.

Nearly 9,000 hospitalizations are used and around 1400 people use the ICU continuously. The number of public hospitals in the Netherlands is 110 , plus 8 hospitals are teaching hospitals / university hospitals. The usual capacity in the Netherlands is normally 1,150 . However, within 3 weeks, all the large hospital buildings were replaced by 2400 ICU units to increase the ICU capacity. Covid-19 patients who are admitted to the ICU will stay for about 3 weeks. Much longer than usual which is only 10 days. So, Covid-19 patients used the ICU for too long if it was taken into account from the beginning of the outbreak.

The area of the Netherlands is almost the same as Central Java. In the Netherlands, every 10 minutes a hospital can be found. In the Netherlands, the third week after February 27, the smart lockdown has been implemented. So far, it has entered the eighth and ninth week. So, smart lockdown has been enforced in the Netherlands for about 5 weeks. Based on the graph as of April 14, 2020, the patient's death rate has decreased, approximately 55. Currently in the Netherlands it is spring. Flowers are blooming. However, currently the Netherlands is deserted due to a smart lockdown. The shopping centers in Amsterdam are also very quiet. The smart lockdown that applies in the Netherlands is when leaving the house to shop for example, not allowed to be together, a maximum of two people, three of them are prohibited. The two of them still have to maintain a distance of 1.5 meters 10 . If violated, you will be fined approximately 400 euros. In addition, washing hands is also mandatory ${ }^{10}$.

\section{The Role of Family Doctors During the Covid-19 Pandemic in the Netherlands}

Every day for 24 hours, the family doctor acts as a health gateway throughout the Netherlands. Family doctors handle $90 \%$ of the difficulties of patients in the Netherlands, while $10 \%$ are accident patients or other emergency patients who can go directly to public hospitals. If the public hospital is unable to handle certain cases, the patient will be referred to the teaching hospital / university hospital. Family doctors cannot directly refer patients to the university hospital. Public hospitals must be treated first, then if they cannot, they can be referred to the university hospital. Currently family doctors in the Netherlands practice in an integrated manner. Family physicians share their practice. The first practice is the practice of Covid-19 risk or what is called red practice. In other buildings it is clean practice / general practice. If there is a non-Covid emergency case or accident, you can use an ambulance and go straight to the hospital. But the gapuras are red practice (family doctor with Covid-19 
risk practice) and green practice (family doctor with clean / general practice). Patients with Covid-19 cannot be treated directly by the hospital, but must be handled by a family doctor first (a family doctor with a Covid-19 risk practice), because it is the family doctor who must provide symptoms or a card for admission. When a pandemic occurs like this, an emergency system is imposed. All doctors cooperate. The doctor will do the triage over the phone. If there is a call from the patient, the family doctor will explain how the patient can come directly to the practice, come to the red or green practice, give advice, what time the patient should come. If the patient is a suspect Covid-19, then the patient is asked to come but remain in the car until the family doctor's assistant comes outside to pick up the patient. Patients will be dressed in infection prevention clothing and given a mask. After that, new patients can go inside to meet the family doctor and indeed the family doctor also wears a mask. If in green practice, the patient is called in to meet the doctor by the patient but does not use any infection prevention equipment and the doctor works as usual. For Indonesia, it is advisable to use the Covid-19 prevention and control guidelines made by the Ministry of Health, because it is really good, the same as in the Netherlands. then the patient is asked to come but remains in the car until the family doctor's assistant comes outside to pick up the patient. Patients will be dressed in infection prevention clothing and given a mask. After that, new patients can go inside to meet the family doctor and indeed the family doctor also wears a mask. If in green practice, the patient is called in to meet the doctor by the patient but does not use any infection prevention equipment and the doctor works as usual. For Indonesia, it is advisable to use the Covid-19 prevention and control guidelines made by the Ministry of Health, because it is really good, the same as in the Netherlands. then the patient is asked to come but remains in the car until the family doctor's assistant comes outside to pick up the patient. Patients will be dressed in infection prevention clothing and given a mask. After that, new patients can go inside to meet the family doctor and indeed the family doctor also wears a mask. If in green practice, the patient is called in to meet the doctor by the patient but does not wear any infection prevention equipment and the doctor works as usual. For Indonesia, it is advisable to use the Covid-19 prevention and control guidelines made by the Ministry of Health, because it is really good, the same as in the Netherlands. New patients can go inside to meet the family doctor and in fact the family doctor also wears a mask. If in green practice, the patient is called in to meet the doctor by the patient but does not wear any infection prevention equipment and the doctor works as usual. For Indonesia, it is advisable to use the Covid-19 prevention and control guidelines made by the Ministry of Health, because it is really good, the same as in the Netherlands. New patients can go inside to meet the family doctor and in fact the family doctor also wears a mask. If in green practice, the patient is called in to meet the doctor by the patient but does not use any infection prevention equipment and the doctor works as usual. For Indonesia, it is advisable to use the Covid-19 prevention and control guidelines made by the Ministry of Health, because it is really good, the same as in the Netherlands.
Smart lockdownwhich is enforced in the Netherlands for about 2 months by calculation, and the most important thing in the Netherlands is the responsibility to fellow human beings. The strength in the Netherlands is that all must be accountable to fellow human beings. Stay at home, leave the house only for urgent purposes, maintain a distance of 1.5 meters, also wash your hands 10 . Luckily, it is very easy to invite people in the Netherlands to take part in fighting Covid-19, although sometimes there are still young people who do not obey the rules of the government, but they will be immediately prosecuted by the police.

In the Netherlands using Gecontroleerd's chart, social distancing and flat the curve. The ICU capacity in the Netherlands has been increased from 1150 units to 2400 units. So that it can accommodate new patients. Currently, it is difficult to determine when the lockdown will be stopped, released or not. According to calculations, more or less until the end of May 2020.

\section{Positive Impact of Covid-19 on Dutch Society}

\section{Impact on Society}

The existence of Covid-19 makes people in the Netherlands more aware about health, cleanliness, risk factors and lifestyle. Many people in the Netherlands are obese, and there are many smokers. With the arrival of Covid-19, the Dutch people have become more aware. Not infrequently those who finally decide to quit smoking. They also maintain their diet more.

About mutual cooperation. The Dutch people are more concerned, especially for the weak and isolated. Sympathy and support for each other, as well as to nurses, doctors, and other personnel. Every day people use computers to talk to each other, with face time, whatsapp, and videos. Then as a token of gratitude for the health team in the Netherlands, many people have made posters as gratitude.

The public's panic was reduced because every week, the central leader through a briefing expert and the minister gave a briefing at a certain time. So, everyone knows what happened, so there is no more hoax news. The briefing will be attended by the Prime Minister and three ministers, namely two Ministers of Health (hospital health and public health) and the Minister of Justice.

When the smart lockdown, apart from being advised to stay at home, leave the house for urgent things such as shopping, looking for food and are prohibited from gathering more than 2 people, schools are also closed, hotels are closed, except for vital objects for transportation, agro-industry, supermarkets and homes. ill still open ${ }^{10}$.

\section{Impact on Government}

The handling of health problems is usually done in a decentralized manner. However, this time it turned into centralization. The media are all united too. All media come together to cover the briefing from the government. For effort, the government provides allowances for losses to companies. Purchasing power is also important. If the tenants of the house are unable to pay the rent or are unable to pay for electricity due to reduced effort or income, it is 
prohibited to evict the tenants.

\section{Impact on Science}

Since the Netherlands has become a united European country, self-supporting has decreased greatly. Whereas 20-30 years ago, the Netherlands had very high selfsupport. The Netherlands has the Gist Brocade factory, the largest antibiotic factory in the world. This factory is gone. Vaccine / drug factory patents are widely sold outside. Then now the government is providing assistance because biotechnology has to return to the Netherlands.

Leantechnology, must be changed even more lean, and the basic ingredients must be met first. Usually everything can be made in the Netherlands. In 3 weeks, the masks can be made by the Dutch themselves, but the funny thing is that the necessary machines come from China.

Innovations in every hospital at this time are really being developed. The gas distribution system, electricity distribution, have already been calculated to be replaced by an ICU. Usual inpatient room, now converted into ICU.

In addition, it also increases the nurse's power. Because the salary of nurses in the Netherlands is very low, many nurses are not willing to work as nurses anymore. They prefer to be traders, and currently in the Netherlands there is a nursing crisis because there are too few nurses. So, the old nurses were asked to come back.

In the Netherlands also use smartphones for tracing. So, when there are people around with Covid-19, it can be detected. So, can be more careful.

\section{Summary}

The Covid-19 pandemic which currently occurring could be viewed positively. We should realize that this pandemic can carries a mission for the benefit of mankind. There are so many positive impacts in various aspects of life with the presence of Covid-19, like the decreasing poluttion on carbodioxide and the increasing hiegene and sanitation habits around the world. Also the increasing use of telemedicine which can save time and place.

To prepare for another upcoming outbreak, a well-prepared response system must be built through training for doctors with simulations of the occurrence of an outbreak and how to deal with the outbreak. The government is also expected to pay more attention to doctors and other health workers, and to provide large investments in the health sector.

Extraordinary events such as the Covid-19 pandemic will cause significant changes that will give birth to a new civilization, namely modernization in the fields of medical education and health services.

\section{REFERENCE}

1. Newton I. The mathematical principles of natural philosophy. Andrew Motte, translator. New York: Daniel Adee; 1846.

2. Cohn S. After the black death: labor legislation and attitudes towards labor in late-medieval western Europe. The Economic History Review. 2007; 60 (3): 457-485.

3. Gregg P. Black death to industrial revolution: a social and economic history of England. New York: Barnes \& Noble; 1976.

4. Bagir ZA. Integration of science and religion: interpretation and action. Bandung: Mizan Pustaka; 2005.

5. Nasution DAD, Erlina, Muda I. The impact of the Covid-19 pandemic on the Indonesian economy. Benefita's Journal. 2020; 5 (2): 212-224.

6. Xia F, Yang LT, Wang L, Vinel A. Internet of things. Int. J. Commun Syst. 2012; 25: 1101-1102.

7. Osuwa AA, Ekhoragbon EB, Fat LT. Application of artificial intelligence in internet of things. 9th International Conference on Computational Intelligence and Communication Network (CICN); 2017: 169-173.

8. Friedman TL. The world is flat: a brief story of the twenty-first century. New York: Farrar, Straus and Giroux; 2005.

9. Public Health Emergency of International Concern. Covid-19. WHO; 2020.https://www.who.int/publications/m/item/Covid-19-publichealth-emergency-of-international-concern-(pheic)-global-researchand-innovation-forum\#: : text $=$ On $\%$ 2030\% 20January $\% 202020 \%$ 20following, of $\% 20$ International $\%$ 20Concern $\% 20$ (PHEIC).

10. de Haas M, Faber R, Hamersma M. How Covid-19 and the Dutch 'intelligent lockdown' change activities, work and travel behavior: evidence from longitudinal data in the Netherlands. Transportation Research Interdisciplinary Perspectives. 2020; 6: 100150.

\section{Questions and Answers}

\section{Q: What is meant by smart lockdown?}

A: If there is a smart lockdown, people are asked to stay at home as much as possible. May leave the house to breathe clean air, but not more than 2 people. People are not allowed to worship in churches, mosques, and are required to implement social distancing at a distance of 1.5 meters. If using transportation, it is allowed to use a car. You can use public transportation, but you must really implement social distancing. Going out of the house only for things that are really important, for example for shopping, going to the hospital, or working in an office that really applies social distancing. More specifically, it is forbidden to gather more than 2 people anywhere. Smart lockdown also means hygienic, wash your hands as often as possible. In the Netherlands, we are not strongly encouraged to wear masks, because they can lead to misperceptions. For example, when wearing a mask, but the hand is holding the mask, there is another risk. Discipline for social distancing is the most important thing.

\section{Q: How about the details of the triage over the phone? Then, how is the application of telephone triage with telemedicine / teleconsultation / telescreening?}

A: Triage in the Netherlands is conducted online, using face time, video and telephone. Indeed, the diagnosis is not as good as when the patient meets the doctor in person, but if the patient does not experience shortness of breath, it can be completed via video. If the patient has a cough, the doctor will prescribe antibiotics. Most doctors will give Amoxicillin. If the patient has too many complaints, the doctor will provide an alternative to Azithromycin. It was both awarded via triage. Both were not normally used, but are now used because the risk is too high for the doctor. Then, each patient will call his / her own family doctor, and the family doctor has an assistant on duty to take the call to ask what complaints the patient feels. If you do experience symptoms such as fever, Symptoms of Covid-19, diarrhea, anosmia, unable to taste food, dry cough, the assistant will forward the phone to the doctor and the doctor will discuss the complaint and provide a diagnosis. If the 
patient really feels that the complaint is very disturbing and the patient says that he is tired of the complaint he feels, these are the symptoms of a red diagnosis, a big risk, the doctor will immediately send an ambulance to pick up the patient, because for example the patient experiences shortness of breath, usually within 1 or 2 hours they can crisis. Therefore, doctors will bring in a special Covid-19 ambulance. If the patient really feels that the complaint is very disturbing and the patient says that he is tired of the complaint he feels, these are the symptoms of a red diagnosis, a big risk, then the doctor will immediately send an ambulance to pick up the patient, because for example the patient experiences shortness of breath, usually within 1 or 2 hours they can crisis. Therefore, doctors will bring in a special Covid-19 ambulance. If the patient really feels that the complaint is very disturbing and the patient says that he is tired of the complaint he feels, these are the symptoms of a red diagnosis, a big risk, the doctor will immediately send an ambulance to pick up the patient, because for example the patient experiences shortness of breath, usually in 1 or 2 hours they can crisis. Therefore, doctors will bring in a special Covid-19 ambulance.

\section{P: How are the steps to make the breakthroughs that have been described? How to react? For example, as an educator, how to react? Then, what about the skills related to breakthroughs in education and health services?}

A: Actually, the capital for handling Covid-19 is already owned, and it is truly extraordinary, but the capital is not used. What capital is that? The first is a smartphone. If a smartphone is connected to a satellite, for example, it can monitor positive people, whether ODP, PDP, and / or suspect. All can be monitored by satellite, where they went and where they were before, so it can be known previous contacts and future contacts. In a sense, contact tracing becomes easier if you connect a smartphone to a satellite. With special orders, everyone's data will be connected, and people with Covid-19 will be detected, where they went and where they were before. So, when Covid-19 began to emerge in Wuhan, it should have been done before the case spread. but it was not done because the response system was not good enough to respond to an outbreak. Even though there have been many disease outbreaks.

In order to have a good response system, of course through training. There must be a lot of training and simulations like a soldier. How the army attacked and defeated the enemy with the various simulations they did, military exercises with various tactics, various scenarios and strategies carried out. Currently, there is no scenario for how to deal with Covid-19 and in the future we do not yet have how to deal with future outbreaks that could be more violent than Covid-19 that is happening today, unless it is prepared from now on. Preparation must be good, everything must be prepared to form a sophisticated response system with trained personnel. General practitioners can be trained to become epidemiologyst fields like army troops if an enemy suddenly attacks, they can in a matter of seconds / minutes send troops, logistics, and so on to the enemy's place, and they have a strategy, staff, command- commandos in various regions and once there are cases, they respond very quickly, there are clear and tested SOPs. There is no such response system. If you already have various scenarios for dealing with future outbreaks, then of course all will be ready and the disease outbreaks will not spread as they are now. Again getting started is through training. Some virus scenarios what will happen in the future can be made and must be predicted from now, as well as trained how to deal with it. With existing technology, it remains how this technology is used. Loss is a country if it does not provide a large investment for health. This must be realized by the government. Investments must be big for health, and what is in smartphones now, in the future will contain various kinds of programs related to health.

\section{Q: How do you do this for people who may not be proficient or literate for technology?}

A: Never underestimate. Today's children from kindergarten have started to know technology. Even now, they are already using e-learning for their learning, even with exams carried out using technology. If you look at students, all of them already understand e-learning, even more proficient. They are increasingly uncomfortable with face-to-face lectures. They are actually comfortable with existing technology because they were born to have met this technology. Likewise with the people in the villages, it is rare to find people who are tech-savvy.

However, the current challenge when physical distancing and/or social distancing is applied is that it is often not connected to information technology, thus making people far apart. This should be related to information technology, so that it is not completely separate and the separation does not occur. It is possible to part with a distance, but the heart must always be close. If information technology can be used as well as possible, then all can be connected. Keep in touch with people far away. That's what sometimes isn't done. So, it is feared that in the future there will be a separation, in fact there will be hostility if we do not correct from now on regarding this physical distancing and / or social distancing.

Q: How to solve the problem of teaching skills for students in the Covid-19 era? And what is the role of coass students in handling Covid-19 in the Netherlands?

A: To treat Covid-19, it is carried out by a family doctor who is a family doctor. Students are prohibited from handling Covid-19 because they have no experience and the risk is too high. These students should only work with patients who are not at risk. So, patients practice green, not red practice. Then, to choose which doctor practices red or green practices depending on the doctor's condition. If the doctor has no comorbidities and is young, then he may work in the red zone. For the green zone are doctors who are somewhat aged and may have comorbidities such as hypertension.

\section{P: His presentation shows a different culture, how to} discipline people for social distancing with awareness?

J: What different cultures can discipline people? Certainly 
can. Number one is that people have to trust the government. People in the Netherlands believe in the government, and leaders from religion, leaders from universities, all have to run through one 'funnel', namely the 'funnel' of the government. The government has a team from a medical team, a virology team, a team of accidents, all made into one team. So, there is only one sound and not mixed up. That is the most important.

Q: How do I get in and out of the Netherlands via airports, international train stations and ports? Opened or not?

A: It is still possible to enter the airport and station, but it depends on where. In the country there is no inspection whatsoever. From abroad depending on which country. For example, between Belgium, France and Germany, all of these are lockdown in Belgium and France, but Germany can enter, are allowed, and there is no inspection. For flights, they can enter, but must have a fit to fly card. For example, people from America can enter but must have a fit to fly card before boarding the plane.

\section{P: How is the completeness of the special Covid-19 ambulance?}

A: Indeed there are ambulances in the Netherlands that are special for carrying Covid-19 patients. The officers wore infection control devices, wore masks and glasses. Glasses are important, glasses that are truly goggles are like diver's glasses.

\section{Q: What is meant by the Covid-19 screening plan via smartphone?}

A: This application is still being made. The government in the Netherlands will run a system that is more or less the same as in Singapore. This application uses bluetooth. Everyone can send data via bluetooth. Data will always be sent in the bluetooth area up to 15 cashews. These data are made by the central government. Data of people who are positive for Covid-19 will be sent via the application. So, for example, when meeting and being close to someone who is positive for Covid-19, you must be careful.

P: Prevention has been done, but if you look at it, Covid-19 cases continue to increase. Why do you think so?

A: This can be caused when the preventive steps are not running seriously and do not comply with the established guidelines. The physical distancing is not carried out seriously. Then, there could be a leak, for example, when a family comes here and there, then goes in and out again, the risk will be even greater. In the Netherlands, if combined between those suspected and those without symptoms, there are around 45,000 people (data as of April 14, 2020). Meanwhile, the number of sicknesses is around 28,000 which is confirmed positive. If you look at the numbers, it rotates at $5-10 \%$, some say $3-5 \%$. So that the striking difference is that this virus is growing very fast, very fast and very much is affected. If counted, the number infected, then the number confirmed, the percentage that should actually be seen. So don't look at how many people died. That is why physical distancing is the keyword for how to avoid a wider spread.

\section{P: What will the future of the Family Medicine service be if everything has been replaced by robots. Is everything really replaceable?}

A: That is the strength of the Family Doctor, because there is the word family. Robots cannot possibly enter families, what must be prepared now is the ability of Family Doctors to master information technology, the ability to build or produce sciences in the field of Family Medicine. Currently there are still many gaps. Killing the gap, which is always socialized, there are still many gaps that must be filled in home care, home visits, and so on. Robots cannot home visit. At least, it's hard if they do that. That is the strength of the Family Doctor. So, the first suggestion is to master technology, make products, don't just study theory and be strong in theory. In theory, the future value will decrease. Your value as a Family Doctor will increase if you can produce products related to Family Medicine. So, the advice in the curriculum for Family Medicine going forward is how to master technology for Family Medicine. IOT is absolute, big data, mastering algorithms. The human body is actually an algorithm. Let's master that knowledge, let's produce artificial intelligence products related to Family Medicine. Doctors need training, and the strength of the Family Doctor is the word family. Family doctors are replaced by robots in hospitals, health centers, and other health services. This is progress, human progress. Doctors no longer need to have close contact with patients as is the case now, which causes many of their fellow doctors and other health workers to become victims. This paper describes how when in Europe there was a shortage of farmers because many of the farmers died because of the plague, the farmers were replaced with agricultural technology, so that the agricultural industry or the first industrial revolution began. Currently, many doctors become victims, and from here it will result in an industrial revolution in the field of medicine to strengthen the position of doctors in the future. It is hoped that the government will pay attention to doctors and other health workers. Respect them, give them high honoraria so that they can be more productive to save this nation. Not only BUMNs that receive high honoraria, but doctors who are directly related to the community for national health must also be considered. If doctors pay more attention,

One thing that cannot be replaced is the family medicine service in the Covid-19 era, namely the psychosocial aspect of the patient. Many services can be replaced by robots, but how doctors interact with patients, the doctor-patient relationship, will not be replaced.

Question: Is it true that you can still infect yourself after someone is declared cured of Covid-19?

A: In fact this is still unknown. The sensitivity of the IgG-IgM rapid test is still unknown. Currently there are approximately 130 tests worldwide. Every manufacturer has a test, but the possibility of sensitivity is not yet high. Many of the risks of false negatives or positives are really 
not positive or negative. So, it is very dangerous to talk about this because it is not certain. Regarding transmitting again after being declared cured, there are actually various possibilities. There are also those who after $1 / 2$ year or 1 year lose their immunity and can be infected again. But it is not certain. Currently what is waiting is a vaccine. If the vaccine does get through, the risk of transmission will be minimal.

Q: Does the weather affect the spread of the Covid-19 virus? How fast has the Netherlands anticipated since entering Covid into the Netherlands from Italy?

A: Regarding the weather factor, maybe this question is because the weather in Indonesia is hot and the weather in Europe is cold. In Europe, because of the cold weather, people prefer to stay indoors. Thus, the risk of transmission in the home is higher. But for the factor of living outside the Indonesian weather doesn't seem affected. The effect on the heat or the cold doesn't really matter. Only the influence factor together, the grouping in Europe is bigger because of the cold weather.
P: Previously there were only 1100 beds in total in the Netherlands for ICU, then during Covid-19 the Dutch Government quickly made it to 2400. Approximately if it was related to the readiness of nurses, especially nurses in ICU, how could the Dutch government be prepare facilities, infrastructure, and also human resources to anticipate Covid-19?

A: Usually one nurse treats 2 patients, but currently nurses are asked to handle 4 patients. This is indeed tough for nurses because they have to keep concentrating on 4 people, usually only 2 people. There are quite a lot of tools in the Netherlands, because approximately every $3 / 4$ of the year, they are considered obsolete and are put in a warehouse. So that at this time the equipment in the warehouse was released again. The handling of Covid-19 in the Netherlands also received assistance from a military hospital. These military hospitals are also used to raise the ICU by 2400 . Ventilatory respiration devices are very important and must be in the ICU. For these devices there is also help from students of the institute of technology, they make additional ventilators. 